\title{
Microcapsules Preparation of Alcohol Extracts from Nymphaea Hybrid and Determination of Its Antioxidant Capability in vitro and in vivo
}

\author{
Shuqin $\mathrm{HANG}^{1}$, Xiaoming SUN ${ }^{1,2,3}$, Yuchen $\mathrm{HE}^{2}$, Jianfeng YUAN ${ }^{1,2 *}$
}

\begin{abstract}
To find efficient natural antioxidants and further improve the utilization value of Nymphaea hybrid, the alcohol extracts from that are embedded and an all-round evaluation for the antioxidant activity is carried out. The microcapsule process is optimized by Box-Behnken response surface analysis which includes the wall-to-core ratio of 3.39:1, inlet air temperature at $195.56^{\circ} \mathrm{C}$, and the homogeneous number of 4.03, exhibiting the highest microencapsulation efficiency (94.36\%). Antioxidant experiments in vitro showed that there was no significant difference between alcohol extracts and microcapsule on $\mathrm{DPPH} \cdot, \cdot \mathrm{O}_{2}^{-}$and $\cdot \mathrm{OH}$, while the scavenging activity of microcapsule on $\mathrm{ABTS}^{+}$. was lower against alcohol extracts. It was worth noting that the activities of GSH, SOD and CAT in vivo were increased about $55.55 \%, 29.13 \%$ and $51.23 \%$. Similar results were obtained with microcapsule treatment. The heat treatment results showed the scavenging activities of alcohol extracts and microcapsule on antioxidant experiments in vitro were all decreased; however, the antioxidant activity of microcapsule was higher than that of alcohol extracts, indicating that the microencapsulation could improve the thermal stability. In conclusion, Nymphaea hybrid alcohol extracts is a well natural antioxidants, moreover, this study provide basic support for comprehensive utilization of Nymphaea hybrid.
\end{abstract}

Keywords: Nymphaea hybrid; alcohol extract; embedding; antioxidant.

Practical Application: The investigated Nymphaea Hybrid alcohol extracts exhibit the well antioxidant activities in vitro and in vivo; Moreover, the microcapsules of that is suitable for development as a natural antioxidants and further improves the valorization of onions.

\section{Introduction}

Perfume Lotus (Nymphaea hybrid) is a large tropical water lily belonging to Nymphaeaceae (Xu et al., 2021), a perennial aquatic flower with rich colors and strong aroma, and is currently mainly used as an ornamental plant. The main ingredients of Nymphaea hybrid are flavonoids (He et al., 2019), polyphenols and polysaccharides (Cong et al., 2018), which have health care functions such as anti-oxidation (Ren et al., 2010), antiaging, whitening and moisturizing (Sun et al., 2018), improving memory, reducing fat and protecting liver (Jiang et al., 2012) and inhibiting prostate hyperplasia (Chen et al., 2015). At present, the composition analysis research of Nymphaea hybrid flower has been more comprehensive, however, the deep processing of the Nymphaea hybrid alcohol extracts is rarely reported. Crucially, the nature of Nymphaea hybrid alcohol extracts is unstable, prone to the influence of various physical and chemical factors. Therefore, improving the stability of Nymphaea hybrid alcohol extracts will be an important premise to broaden the Nymphaea hybrid processing and application.

Microencapsulation is a technique in which one or more components bury a certain matrix through natural polymer materials, thus realizing the effective delivery of embedding materials, which can protect the active substances from the environment impact, improve its oxidation stability, and have a slow release effect (Dias et al., 2015). The preparation of microcapsules, a spray drying method, is one of the most commonly used techniques in the food industry for the protection of functional compounds (Meng et al., 2019). The main advantages of this method are stable product performance, a variety of wall materials available, good product form, low cost, convenient operation and suitable for industrial production.

In this study, we will extract the Nymphaea hybrid active ingredients easily soluble in alcohol and bury it. With the aim of research, Box-Behnken response surface analysis is used to optimize the embedding conditions and determine the antioxidant capacity, providing a scientific basis for the development and utilization of Nymphaea hybrid.

\section{Materials and methods}

The Nymphaea hybrid is provided by Jinhua Academy of Agricultural Sciences (Jinhua, China) and preserved at $-80^{\circ} \mathrm{C}$ until use; $\beta$-cyclodextrin, maltodextrin, arabic gum powder are purchased from Shenggong Biological Engineering Co., LTD., (Shanghai, China); Other reagents are all analytical purity. 


\subsection{Preparation of alcohol extracts from Nymphaea hybrid}

Dried Nymphaea hybrid flower are smashed and passed through 80 mesh, then placed 20.0 g powder in $500 \mathrm{~mL}$ conical bottle, followed by adding $200 \mathrm{~mL}$ ethanol solution (80\%). The alcohol extracts mixture from Nymphaea hybrid is obtained with ultrasonic treatment $(200 \mathrm{~W}, 40 \mathrm{~Hz})$ for $1 \mathrm{~h}$. Finally, the alcohol extracts mixture is evaporated and concentrated, and the Nymphaea hybrid alcohol extracts powder is obtained by freeze drying.

\subsection{Embedding of alcohol extracts of Nymphaea hybrid}

Wall material, sucrose fatty acid esters and water are mixed and dissolved in a certain proportion, then Nymphaea hybrid alcohol extracts powder is added, which is homogenized emulsion and subjected to spray drying to prepare microcapsules.

\section{Single factor test}

The wall-to-core ratio $(2: 1 / 3: 1 / 4: 1 / 5: 1 / 6: 1)$, inlet temperature $\left(170{ }^{\circ} \mathrm{C} / 180^{\circ} \mathrm{C} / 190^{\circ} \mathrm{C} / 200^{\circ} \mathrm{C} / 210^{\circ} \mathrm{C}\right)$ and homogenization times $(0 / 1 / 3 / 5 / 7)$ on the embedding effect are investigated, with the compound capsule wall material ( $\beta$-cyclodextrin:m altodextrin:arabic gum powder $=7: 4: 9)$. For microcapsules, there is a positive correlation between the embedding yield and the embedding rate, therefore, the appropriate wall-core ratio, homogenization times, inlet temperature and their corresponding ranges are determined. Through the measurement and analysis of the embedding rate and data processing. (Aberkane et al., 2014)

Response surface test design

On the basis of single factor test, the Box-Behnken design (response surface method of 3 factor 3 level) is adopted to optimize the processes of alcohol extracts microcapsules (Premjit \& Mitra, 2021). The influence of wall-to-core ratio (A, 3:1-5:1), inlet temperature $\left(\mathrm{B}, 180^{\circ} \mathrm{C}-200^{\circ} \mathrm{C}\right)$ and homogenization times (C, 3-7) on the response value, embedding yield (Y, \%), are analyzed. The Box-Behnken design is shown in Table 1.

\section{Determination of embedding rate}

Referring to Liu et al. (2020), the surface oil content and total oil content are determined, and the sample embedding rate (\%) is calculated according to the formula below (Equation 1).

the embedding rate $(\%)=\left(1-\frac{\text { Surface oil content }}{\text { the total oil content }}\right) \times 100 \%$

Table 1. Combined test factors and horizontal design of Box-Behnken center.

\begin{tabular}{cccc}
\hline & \multicolumn{3}{c}{ factors } \\
\cline { 2 - 4 } Level & $\mathrm{A}$ & $\mathrm{B}$ & $\mathrm{C}$ \\
& (wall-core ratio) & (inlet temperature) & (homogenization times) \\
\hline-1 & $3: 1$ & $180^{\circ} \mathrm{C}$ & 3 \\
0 & $4: 1$ & $190^{\circ} \mathrm{C}$ & 5 \\
1 & $5: 1$ & $200^{\circ} \mathrm{C}$ & 7 \\
\hline
\end{tabular}

\subsection{Antioxidant activity of Nymphaea hybrid flower microcapsules in vitro}

\section{$D P P H \cdot$ free radical quenching capacity determination}

$\mathrm{DPPH}$ - radical degradation method is used to estimate the antioxidant activity. A certain mass of Nymphaea hybrid microcapsules are taken, and dissolved in 2\% DMSO solution, preparing into different concentrations $(0.1-2.5 \mathrm{mg} / \mathrm{mL})$ sample solutions. Referring to the experimental method of Sarker et al. (2020), A UVmini-1240 spectrophotometer (SHIMADZU, Japan) is used to measure the absorbance at $517 \mathrm{~nm}$ (Equation 2).

$\mathrm{DPPH} \cdot$ quenching rate $=\frac{A_{0}-\left(A_{i}-A_{j}\right)}{A_{0}} \times 100 \%$

Where, $A_{0}$ is blank control absorbance, $A_{i}$ is absorption of sample group, and $A_{j}$ is the absorbance of negative control group.

\section{$A B T S^{+} \cdot$ radical quenching capacity determination}

The method of Li et al. (2021) is followed for $\mathrm{ABTS}^{+}$. assay. The Nymphaea hybrid microcapsules and negative control Vc were prepared into $5.0,1.0,0.5,0.1,0.01$ and $0.001 \mathrm{mmol} / \mathrm{mL}$ solution, respectively. $50 \mu \mathrm{L}$ sample of each is added into 96 well cell culture plate, and then $150 \mu \mathrm{L}$ of $\mathrm{ABTS}^{+}$solution is added to each well. After incubated at room temperature for $6 \mathrm{~min}$, the absorbance at $734 \mathrm{~nm}$ is detected. The $\mathrm{ABTS}^{+}$. quenching rate (\%) is as follow (Equation 3).

$\mathrm{ABTS}^{+}$. quenching rate $=\frac{A_{0}-\left(A_{i}-A_{j}\right)}{A_{0}} \times 100 \%$

Where, $A_{0}$ is blank control absorbance, $A_{i}$ is absorption of sample group, and $A_{j}$ is the absorbance of negative control group.

\section{$\cdot \mathrm{O}_{2}^{-}$radical quenching capacity determination}

The assay for measuring $\cdot \mathrm{O}_{2}$ - generation is based on the SOD-inhibitable reduction of ferricytochrome $c$ as described by Kuo et al. (2021) (Equation 4).

$$
\mathrm{O}_{2}{ }^{-} \text {quenching rate }=\frac{A_{0}-\left(A_{i}-A_{j}\right)}{A_{0}} \times 100 \%
$$

Where, $A_{0}$ is blank control absorbance, $A_{i}$ is absorption of sample group, and $A_{j}$ is the absorbance of negative control group.

\section{-OH radical quenching capacity determination}

Referring to Wang et al. (2021), $0.5 \mathrm{~mL}$ of FeSO ${ }_{4}$ solution $(15 \mathrm{mmol} / \mathrm{L})$ and $1 \mathrm{~mL}$ of Nymphaea hybrid alcohol extracts microcapsules solution with different concentration $(2,4,6,8$, $10 \mathrm{mg} / \mathrm{mL}$ ) are mixed, and $50 \mathrm{\mu L} \mathrm{H}_{2} \mathrm{O}_{2}$ with volume fraction of $0.03 \%$ is added to start the reaction, incubated at $37^{\circ} \mathrm{C}$ for $10 \mathrm{~min}$. Finally, $150 \mu \mathrm{L}$ of salicylic acid ethanol solution $(20 \mathrm{mmol} / \mathrm{L})$ is added. The reaction is finished within $30 \mathrm{~min}$ at $37^{\circ} \mathrm{C}$, then the absorbance at $562 \mathrm{~nm}$ is measured (Equation 5).

OH quenching rate $=\frac{A_{0}-\left(A_{i}-A_{j}\right)}{A_{0}} \times 100 \%$ 
Where, $A_{0}$ is blank control absorbance, $A_{i}$ is absorption of sample group, and $A_{j}$ is the absorbance of negative control group.

\subsection{Effects of Nymphaea hybrid alcohol extracts on Caenorhabditis elegans (C.elegans)}

Culture and treatment of C. elegans

Wild-type C. elegans strain N2 and Escherichia coli OP50 are gifted from Nanjing Institute for Comprehensive Utilization of Wild Plants (Nanjing, China). Worms are cultured at $20^{\circ} \mathrm{C}$ in a nematode growth medium (NGM) (Wang et al., 2013) with Escherichia coli OP50 (E. coli OP50) as food, which are described previously. When a large number of eggs appear in C.elegans, the gravid hermaphrodites are lysed by fresh lysate solution ( $5 \mathrm{~mL} 10 \%$ sodium hypochlorite, $5 \mathrm{~mL} \mathrm{1mol} / \mathrm{L}$ sodium hydroxide). Then eggs are washed 3-4 times with M9 buffer, and collected by centrifugation(Wang et al., 2010). The collected eggs are hatched at $20^{\circ} \mathrm{C}$ for $24 \mathrm{~h}$ to gain the $\mathrm{L} 1$ worms, which are transferred to a fresh NGM with E. coli OP50. L2 age-synchronized worms are obtained $1 \mathrm{~d}$ after synchronization.

\section{Exposure method}

For in vivo tests of bioactive function, $0.1 \mathrm{~mL}$ of Nymphaea hybrid alcohol extracts or microcapsules solution $(0.1 \mathrm{mg} / \mathrm{mL})$ are spread on a L2 age-synchronized worms NGM plate, and cultured at $20^{\circ} \mathrm{C}$ for $2 \mathrm{~d}$ to gain L4 aged worms, while M9 buffer is used as control.

\section{Antioxidant enzymes assay}

Continue with the previous steps, $0.1 \pm 0.05 \mathrm{~g} \mathrm{~L} 4$ aged worms of each group are collected and transferred to $1.5 \mathrm{~mL}$ sterile Eppendorf tube containing $1.0 \mathrm{~mL}$ 0.9\% physiological saline. The worms are sonicated on ice with an ultrasonic cell crusher (SCIENTZ, Ningbo, China, JY92-IID). After centrifuged at $2500 \mathrm{r} / \mathrm{min}$ for $10 \mathrm{~min}$, the supernatants are transferred to a new sterile Eppendorf tube. The activities of Superoxide dismutase (SOD) (Wang et al., 2014), catalase (CAT) (Huang et al., 2017) and glutathione (GSH) (Xiong et al., 2012) of C. elegans in each group are measured according to the operation requirements of the kits produced by Nanjing Jian-Cheng Institute of Biological Engineering.

\subsection{Effect of temperature on the stability of alcohol extract and microcapsules}

$1 \mathrm{~g}$ of the alcohol extracts and microcapsules are stored at $40^{\circ} \mathrm{C}$ and $50^{\circ} \mathrm{C}$ under dark conditions respectively for $1 \mathrm{~h}, 2 \mathrm{~h}, 3 \mathrm{~h}$, $4 \mathrm{~h}$ and $5 \mathrm{~h}$, then samples are measured the antioxidant activity.

\subsection{Data statistics and analysis}

Data are presented as mean \pm standard deviation (SD). Statistical analysis is performed using the SPSS 19.0 software (IBM, Chicago, IL, USA) and graphic plotted by Origin 9.1 software. Design-Expert 8.0.6 is used for statistically analyzing the response surface test data (Xiao et al., 2017). Differences in the mean values between treated samples and control are compared by $t$-test (significance at $\mathrm{P}<0.05$ ).

\section{Results and analysis}

\subsection{Preparation of microcapsules of alcohol extract from Nymphaea hybrid}

Effect of wall-to-core ratio on microcapsules

It can be seen that with the increasing of wall-core ratio, the microcapsule embedding rate ( $\bullet$ ) is increased first and then decreased (Figure 1a). When the wall-to-core ratio is $4: 1$, the embedding rate reaches the maximum value of $93.28 \% \pm 0.27 \%$. When the wall-to-core ratio is relatively low, because of the less wall material, the alcohol extracts can not be completely embedded. On the contrary, when the wall-to-core ratio is too high, the wall material is not fully utilized (Maes et al., 2021), and the proportion of alcohol extracts embedded in the microcapsule is reduced, resulting in a decrease of the entrapment rate (Lan et al., 2021).

\section{Effect of inlet air temperature on microcapsule}

For the microencapsulation, the inlet air temperature of spray drying is more crucial. It is elucidated that the embedding rate of microcapsule (-) is the highest, $93.32 \% \pm 0.18 \%$, with the inlet air temperature of $190{ }^{\circ} \mathrm{C}$ (Figure 1b). Within this temperature range, the higher the inlet air temperature, the shorter the drying time of the microcapsule, and the better microcapsule can be formed. It should be noted that when the air inlet temperature is high beyond $190^{\circ} \mathrm{C}$, the microcapsule moisture evaporates too fast, leading to the looseness and destruction of the outer wall structure of the microcapsule, thus affecting the embedding effect of the alcohol extracts (Wang et al., 2018).

\section{Effect of homogenization times on microcapsule}

Homogenization can increase the stability of the emulsion. As shown in Figure 1c, when the homogenization times are 5 times, the embedding rate reaches the maximum value of 93.24\% $\pm 0.23 \%$. Nevertheless, excessive homogenization will lead to the dispersion of wall and core materials, while the high temperature generated by machines may also damage to wall and core materials, reducing the embedding rate and quality of microcapsule (Wang et al., 2020).

\subsection{Response surface methodology to optimize the embedding process}

Establishment of regression equation and analysis of variance (ANOVA)

The response surface design and results are shown in Table 2. The polynomial mathematical model of the data is calculated by Design-expert 8.0.6 software, and the regression model formula is obtained as Embedding rate $=93.69-0.95 \mathrm{~A}+1.33 \mathrm{~B}-0.052 \mathrm{C}$ $-0.80 \mathrm{AB}+1.49 \mathrm{AC}-1.68 \mathrm{BC}-1.73 \mathrm{~A}^{2}-2.37 \mathrm{~B}^{2}-1.96 \mathrm{C}^{2}$ 。 

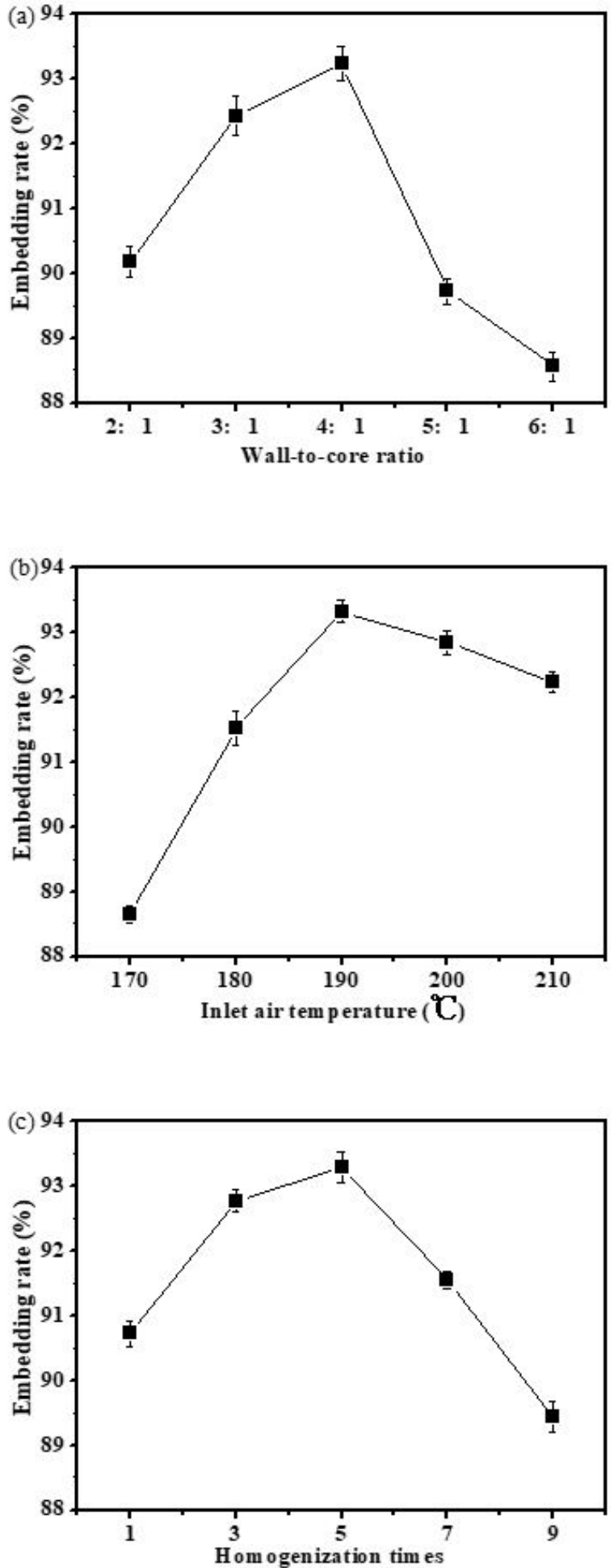

Figure 1. Preparation of microcapsule of alcohol extracts from Nymphaea hybrid. (a) Effect of wall-to-core ratio on microcapsule; (b) Effect of inlet air temperature on microcapsule; (c) Effect of homogenization times on microcapsule. - embedding rate.

According to Table 3 , the p value of this model is less than 0.01 , which has significant difference, while the lack of fit is more than 0.05 , which is not significant, indicating that this
Table 2. Box-Behnken design and results.

\begin{tabular}{ccccc}
\hline Test number & A & B & C & Embedding rate\% \\
\hline 1 & -1 & 1 & 1 & 87.62 \\
2 & 1 & 1 & -1 & 87.36 \\
3 & 1 & 1 & 0 & 89.23 \\
4 & 0 & 0 & 0 & 93.28 \\
5 & 1 & 0 & 0 & 89.91 \\
6 & -1 & 0 & 0 & 92.45 \\
7 & 1 & -1 & 0 & 88.25 \\
8 & -1 & -1 & 1 & 86.24 \\
9 & 1 & 1 & -1 & 87.41 \\
10 & -1 & -1 & 0 & 89.45 \\
11 & 0 & -1 & 0 & 89.53 \\
12 & 0 & 0 & -1 & 92.24 \\
13 & 0 & 0 & 1 & 92.17 \\
14 & -1 & -1 & -1 & 85.98 \\
15 & 1 & 0 & 0 & 92.03 \\
16 & 0 & 1 & 0 & 92.84 \\
17 & 0 & 1 & 1 & 88.67 \\
\hline
\end{tabular}

Table 3. Analysis of ANOVA.

\begin{tabular}{lccccc}
\hline \multicolumn{1}{c}{ Source } & $\begin{array}{c}\text { Sum of } \\
\text { squares }\end{array}$ & Df & $\begin{array}{c}\text { Mean } \\
\text { square }\end{array}$ & F & P-value \\
\hline Model & 87.82 & 9 & 9.76 & 14.30 & $0.0010^{* * *}$ \\
A wall-to-core ratio & 4.20 & 1 & 4.20 & 6.15 & $0.0422^{* *}$ \\
B inlet air temperature & 6.35 & 1 & 6.35 & 9.31 & $0.0186^{* *}$ \\
C homogenization times & 0.012 & 1 & 0.012 & 0.018 & $0.8978^{*}$ \\
AB & 1.26 & 1 & 1.26 & 1.85 & $0.2164^{*}$ \\
AC & 1.12 & 1 & 1.12 & 1.64 & $0.2405^{*}$ \\
BC & 1.98 & 1 & 1.98 & 2.90 & $0.1322^{*}$ \\
$\mathrm{~A}^{2}$ & 6.77 & 1 & 6.77 & 9.92 & $0.0162^{* *}$ \\
$\mathrm{~B}^{2}$ & 13.62 & 1 & 13.62 & 19.96 & $0.0029^{* * *}$ \\
$\mathrm{C}^{2}$ & 8.41 & 1 & 8.41 & 12.33 & $0.0098^{* * *}$ \\
Residual & 4.78 & 7 & 0.68 & & \\
Lack of fit & 2.53 & 5 & 0.51 & 0.69 & $0.6810^{*}$ \\
Pure error & 2.25 & 2 & 1.12 & & \\
Cor. total & 92.59 & 16 & & & \\
\hline Ne: & & &
\end{tabular}

Note: ${ }^{*}$ no difference; ${ }^{* *}$ significant difference; ${ }^{* * *}$ extremely significant difference.

polynomial mathematical model has a good fitting degree to the trial (Song et al., 2017). A, B, and $\mathrm{A}^{2}$ have a significant effect on the embedding rate, but $\mathrm{B}^{2}$ and $\mathrm{C}^{2}$ have a very significant effect on yield. The order of factor response obtained by $\mathrm{F}$ test is as follows: air inlet temperature > wall-to-core ratio > homogenization times.

\section{Validation experiment}

Process optimization is carried out according to the established model, and the optimum process conditions are wall-to-core ratio 3.39, inlet air temperature $195.56^{\circ} \mathrm{C}$, homogenization times 4.03 , and the theoretical embedding rate can reach $94.36 \%$. To be more fit with the actual situation, the wall-to-core ratio, air inlet temperature and homogenization times are $3.39: 1,195^{\circ} \mathrm{C}$, and 4 , respectively. Under this conditions, three parallel validation experiments are carried out. The actual results (embedding rate, 
$94.03 \% \pm 0.12 \%$ ) is showed high agreement with the theoretical values, and the model is well fit.

\subsection{Determination of antioxidant activity in vitro}

The DPPH., ABTS $^{+}, \cdot \mathrm{O}_{2}^{-}$, and $\cdot \mathrm{OH}$ scavenging activities of Nymphaea hybrid alcohol extracts and microcapsule are shown in Table 4. Generally, the Nymphaea hybrid alcohol extracts have a good scavenging effect on DPPH. The scavenging rate of $0.1 \mathrm{mg} / \mathrm{mL}$ alcohol extracts can reach $41.71 \% \pm 1.42 \%$, which is $75.63 \%$ of that of $\mathrm{Vc}$ at the same concentration. The scavenging rates of $\mathrm{ABTS}^{+}$. radical and $\cdot \mathrm{O}_{2}{ }^{-}$are $25.14 \% \pm 1.98 \%$ and $30.96 \% \pm 1.38 \%$, respectively, which are $69.39 \%$ and $67.26 \%$ of Vc. For $\cdot \mathrm{OH}$ radical, the scavenging rate is, $17.38 \pm 2.61 \%$, slightly lower than other free radicals with the effect of $51.19 \%$ against Vc. After embedding, the scavenging rate to $\mathrm{ABTS}^{+}$. is $20.19 \pm 0.99 \%$, which is significantly lower than that of the alcohol extracts, while the scavenging rate of other three free radicals is slightly lower than that of the alcohol extracts, with no significant difference. For microencapsulation, the release efficiency of functional factors will be reduced by the wall material, so the antioxidant effect will also be lower than that of the alcohol extracts. Overall, the Nymphaea hybrid alcohol extracts microcapsule still has certain antioxidant capacity in vitro.

\subsection{Antioxidant properties in C. elegans}

C. elegans are treated by $0.1 \mathrm{mg} / \mathrm{mL}$ Nymphaea hybrid alcohol extracts and $0.1 \mathrm{mg} / \mathrm{mL}$ microcapsule solution with $\mathrm{M} 9$ solution as blank control. The relative values of the antioxidant enzymes GSH, SOD, and CAT in C. elegans are shown in Figure 2. Compared with the control group, the antioxidant enzymes of $C$. elegans in trial group are obviously enhanced, however, the antioxidant enzyme activities, treated by alcohol extracts, are higher than that by microcapsule. As is seen from Figure 2a, the GSH activity, treated by alcohol extracts, is $41.96 \pm 3.07 \mathrm{U} / \mathrm{mgprot}$, over the blank group by $55.55 \%$, while that treated by microcapsule is over $42.72 \%$ against control group. The SOD and CAT enzyme activities are similar with the GSH activity, and enzyme activities treated by alcohol extracts are both higher than that by microcapsule. It is showed that the SOD and CAT activities are $11.72 \pm 1.13 \mathrm{U} /$ mgprot and $13.45 \pm 1.21 \mathrm{U} / \mathrm{mgprot}$, respectively in alcohol extracts group, yet it is $9.89 \pm 0.67 \mathrm{U} / \mathrm{mgprot}$ and $11.7 \pm 0.88 \mathrm{U} /$ mgprot, respectively in microcapsule group (Figure 2b, 2c). Conclusively, Nymphaea hybrid alcohol extracts, to a certain extent, can improve the antioxidant enzyme activities of C. elegans.

\subsection{Influence of temperature on the stability of alcohol extracts and microcapsule}

To evaluate the thermal stability of alcohol extracts and microcapsule, the different free radicals scavenging activities are assayed treated by different temperature and time. In the light of Figure 3, with the heat treatment time increasing, the antioxidant capacities of alcohol extracts and microcapsule are all decreased. The clearance rate of $\mathrm{DPPH} \cdot \mathrm{ABTS}^{+}$., $\cdot \mathrm{O}_{2}$, and $\cdot \mathrm{OH}$ radical decreased $11.5 \%, 10.5 \%, 10.62 \%$ and $5.92 \%$, respectively, when the alcohol extracts are treated at $40{ }^{\circ} \mathrm{C}$ for
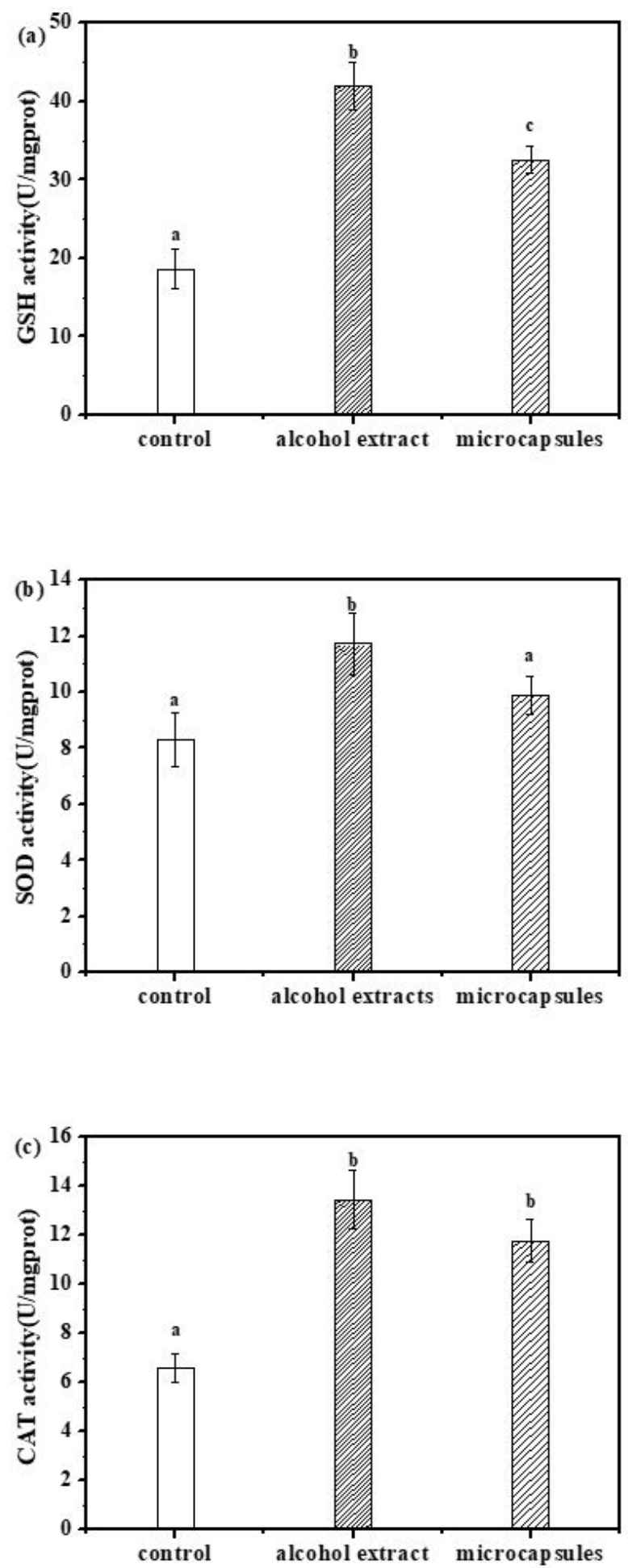

Figure 2. Antioxidant properties in C. elegans. (a) GSH activity; (b) SOD activity; (c) CAT activity Different letters (a, b, c) indicate significant differences $(\mathrm{P}<0.05)$.

$5 \mathrm{~h}$. While these of microcapsule are decreased $6.94 \%, 5.4 \%$, $5.8 \%$ and $3.71 \%$ under the same condition (Figure 3 ). When it is treated at $50{ }^{\circ} \mathrm{C}$ for $5 \mathrm{~h}$, that four free radicals clearance rate of alcohol extract are decreased 19.2\%, 15.06\%, 19.14\% and 
Table 4. Free radical scavenging activity of Nymphaea hybrid alcohol extracts and microcapsule.

\begin{tabular}{|c|c|c|c|}
\hline Antioxidant activity index & $\begin{array}{c}\mathrm{Vc} \\
0.1 \mathrm{mg} / \mathrm{mL}\end{array}$ & $\begin{array}{c}\text { Alcohol extracts } \\
0.1 \mathrm{mg} / \mathrm{mL}\end{array}$ & $\begin{array}{c}\text { Microcapsule } \\
0.1 \mathrm{mg} / \mathrm{mL}\end{array}$ \\
\hline DPPH. & $55.15 \pm 2.21 \%^{\mathrm{a}}$ & $41.71 \pm 1.42 \%^{\mathrm{b}}$ & $38.77 \pm 1.33 \%^{\mathrm{b}}$ \\
\hline ABTS $^{+}$. & $36.23 \pm 2.01 \%^{\mathrm{a}}$ & $25.14 \pm 1.98 \%^{\mathrm{b}}$ & $20.19 \pm 0.99 \%^{c}$ \\
\hline$\cdot \mathrm{O}_{2}^{-}$ & $41.57 \pm 4.18 \%^{\mathrm{a}}$ & $30.96 \pm 1.38 \%^{\mathrm{b}}$ & $27.55 \pm 1.35 \%^{\mathrm{b}}$ \\
\hline. $\mathrm{OH}$ & $33.95 \pm 3.44 \%^{\mathrm{a}}$ & $17.38 \pm 2.61 \%^{\mathrm{b}}$ & $13.28 \pm 1.86 \%^{\mathrm{b}}$ \\
\hline
\end{tabular}

Note: Different letters on the same line indicate significant differences $(\mathrm{P}<0.05)$.
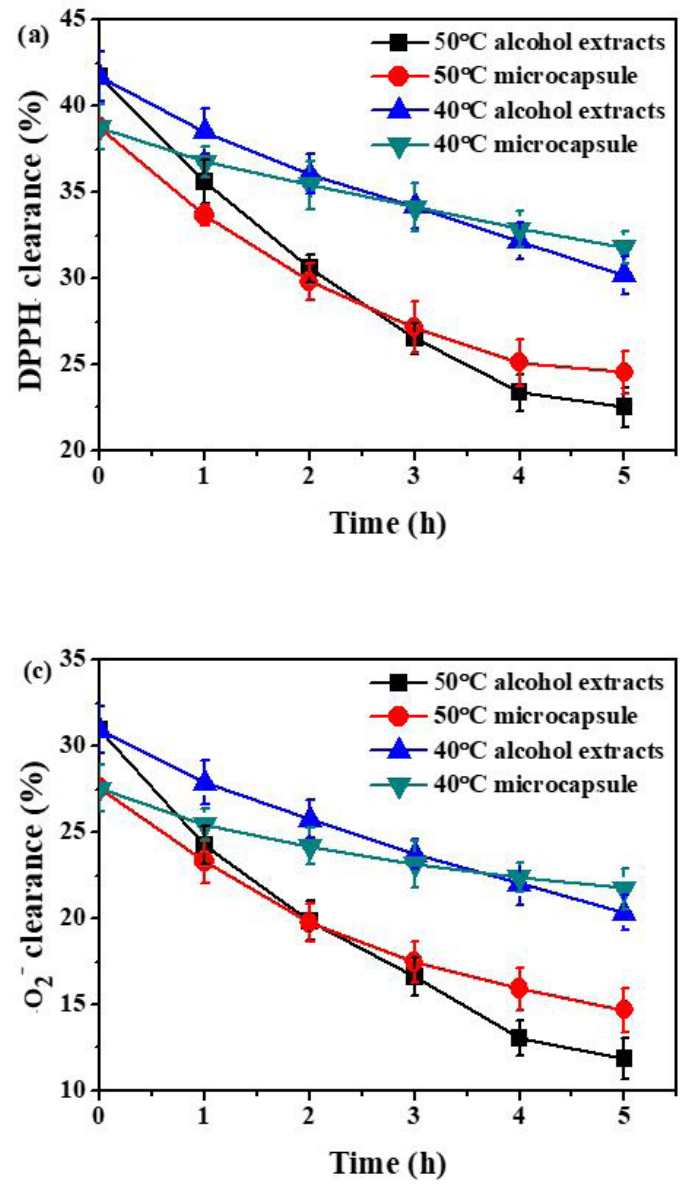
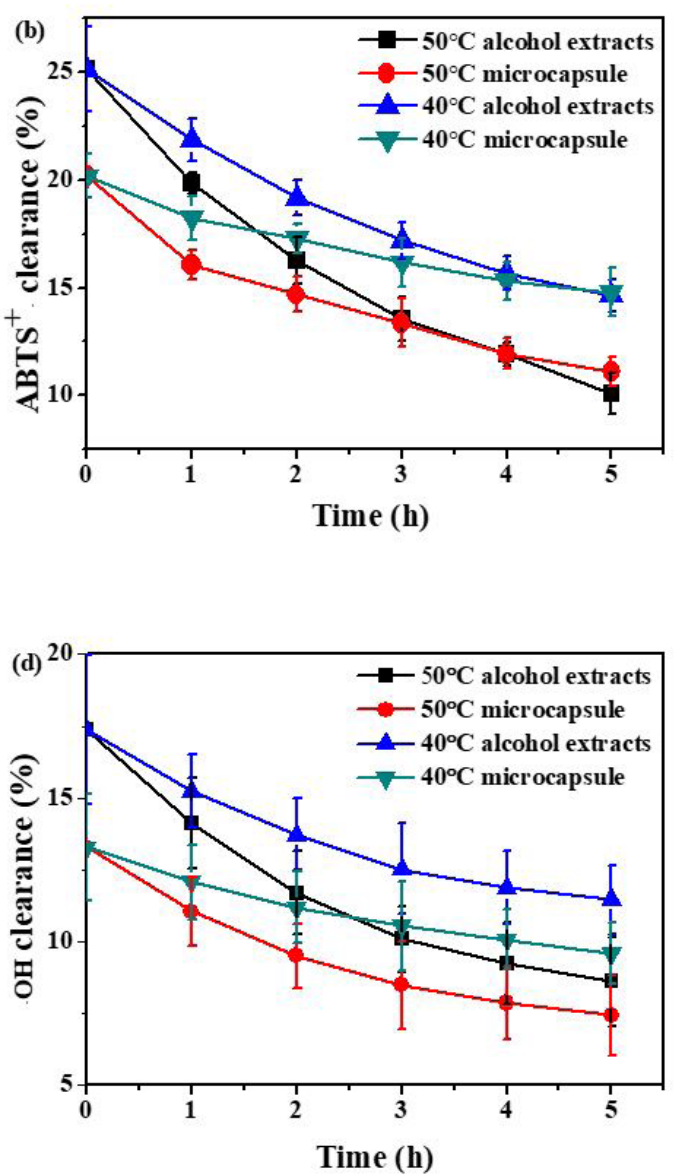

Figure 3. The free radicals clearance rates by alcohol extracts and microcapsule from Nymphaea hybrid at $40{ }^{\circ} \mathrm{C}$ and $50{ }^{\circ} \mathrm{C}$.

$8.77 \%$, and microcapsule by $14.22 \%, 9.11 \%, 12.86 \%$ and $5.85 \%$, respectively. Thus we can see that the clearance of free radicals by microcapsule is decreased less than that by alcohol extracts, and with the heat treatment time increased, in particular heat treated for $5 \mathrm{~h}$, the free radicals clearance rate of microcapsule are all higher than those of the alcohol extracts. In summary, the thermal stability of Nymphaea hybrid alcohol extracts can be effectively improved by microencapsulation.

\section{Conclusion}

Successful results of parameters of Nymphaea hybrid alcohol extracts, wall-to-core ratio, air inlet temperature, and homogenization times, have been obtained by the response surface method. The optimal parameters are wall-core ratio 3.39:1, inlet air temperature $195.56^{\circ} \mathrm{C}$, and homogenization times 4.03 . In this way, the theoretical embedding rate can reach $94.36 \%$, and the verification results have high agreement with the theoretical value.

Alcohol extracts display a certain ability to scavenge free radicals in vitro, and free radicals scavenging effect is $\mathrm{DPPH}$. $>\mathrm{ABTS}^{+} \cdot>\cdot \mathrm{O}_{2}^{-}>\cdot \mathrm{OH}$. Concurrently, the alcohol extracts also spread the good potential to enhance the activity of antioxidant enzymes of C. elegans, in vivo. Compared with the control group, the activities of GSH, SOD and CAT are all increased more than $30 \%$. More importantly, microencapsulation can effectively improve the thermal stability of the Nymphaea hybrid alcohol extracts, which provides convenience for the processing of alcohol extracts.

Considering the potential healthcare benefits of Nymphaea hybrid, primary processing products, such as Nymphaea hybrid tea, are appeared on the market. In this paper, we extensively 
investigate the preparation of Nymphaea hybrid alcohol extracts and its antioxidant properties in vitro and in vivo. Microencapsulation can also prolong the term of validity of active ingredients in Nymphaea hybrid, which lay the foundation for broadening the application scope of Nymphaea hybrid and developing related food.

\section{Acknowledgements}

This work is supported by General Project of Zhejiang Education Department (No. Y201840796), and Key Research Project of Jinhua Science and Technology (No. 2020-2-013).

\section{References}

Aberkane, L., Roudaut, G., \& Saurel, R. (2014). Encapsulation and oxidative stability of pufa-rich oil microencapsulated by spray drying using pea protein and pectin. Food and Bioprocess Technology, 7(5), 1505-1517. http://dx.doi.org/10.1007/s11947-013-1202-9.

Chen, L., Wu, X. V. Q., Zheng, Q. V. Q., Shen, J., Lu, F., \& Shen, J. F. (2015). Experimental study on inhibition of prostatic hyperplasia in rats by nymphaea hybrid. Journal of Chinese Institute of Food Science and Technology, 15(002), 28-33.

Cong, H. X., Hu, G. S., Wang, W. C., Xie, X. H., Lu, J., \& Yao, L. (2018). Study on protein removal and antioxidant activity of crude polysaccharide from Nympheae hybrid. Journal of Shanghai Jiaotong University, 36(06), 49-53.

Dias, M. I., Ferreira, I. C. F. R., \& Barreiro, M. F. (2015). Microencapsulation of bioactive for food applications. Food \& Function, 6(4), 1035-1052. http://dx.doi.org/10.1039/C4FO01175A. PMid:25710906.

He, W. T., Lin, L., Chen, Y. C., Chen, H., \& Deng, S. G. (2019). Study on the optimum extraction technology and antioxidant activity of total flavonoids from lotus. Journal of Zhejiang Ocean University, 38(5), 436-441.

Huang, R. T., Huang, Q., Wu, G. L., Chen, C. G., \& Li, Z. J. (2017). Evaluation of the antioxidant property and effects in Caenorhabditis elegans of Xiangxi flavor vinegar, a Hunan local traditional vinegar. Journal of Zhejiang University. Science. B., 18(4), 324-333. http:// dx.doi.org/10.1631/jzus.B1600088. PMid:28378570.

Jiang, H. F., Jin, J. H., Zhao, B. T., \& Zhang, W. M. (2012). Study on protective effects of nymphaea hybrid on acute alcohol liver injury in mice. Zhongguo Yesheng Zhiwu Ziyuan, 31(005), 18-19.

Kuo, P., Li, Y., Kusuma, A., Tzen, J. T. C., Hwang, T., Ye, G., Yang, M., \& Wang, S. (2021). Anti-inflammatory principles from the needles of pinus taiwanensis hayata and in silico studies of their potential anti-aging effects. Antioxidants, 10(4), 598. http://dx.doi.org/10.3390/ antiox10040598. PMid:33924612.

Lan, Y., Ohm, J., Chen, B., \& Rao, J. (2021). Microencapsulation of hemp seed oil by pea protein isolate sugar beet pectin complex coacervation: Influence of coacervation $\mathrm{pH}$ and wall/core ratio. Food Hydrocolloids, 113, 106423. http://dx.doi.org/10.1016/j. foodhyd.2020.106423.

Li, C. L., Meng, X. H., Shang, X. Y., Zhao, Y. M., \& Yang, J. L. (2021). Pepper chemical composition and its antioxidant activity. Chinese Herbal Medicines, 52(10), 2869-2875.

Liu, X. Y., Wan, R. K., Fan, Y. W., Xiao, J. Y., Cong, R. H., \& Deng, Z. Y. (2020). The process of EPA algae oil microcapsule and the change of fatty acid composition. Journal of Chinese Institute of Food Science and Technology, 20(3), 121-129.

Maes, C., Brostaux, Y., Bouquillon, S., \& Fauconnier, M. L. (2021). Use of new glycerol-based dendrimers for essential oils encapsulation: optimization of stirring time and rate using a plackett-burman design and a surface response methodology. Foods, 10(2), 207. http://dx.doi. org/10.3390/foods10020207. PMid:33498387.

Meng, X. Y., Zhao, Y. Q., Li, Y. K., Li, Y. Q., Xiao, H., Xiao, Y., \& Yang, M. L. (2019). Preparation of anthocyanin from hibiscus sabdariffa microcapsules and evaluation of stability and release. Science and Technology of Food Industry, 14, 174-181.

Premjit, Y., \& Mitra, J. (2021). Optimization of electrospray-assisted microencapsulation of probiotics (leuconostoc lactis) in soy protein isolate-oil particles using box-behnken experimental design. Food and Bioprocess Technology, 14, 1730-1732. http://dx.doi.org/10.1007/ s11947-021-02687-y.

Ren, H. R., Shan, C. Y., Jiang, H. F., Zhang, J., \& Zhang, W. M. (2010). Study on antioxidant activity of ethanol extract from the flower of Nymphaea hybrid. Food Science and Technology, 035(003), 200-203.

Sarker, U., Hossain, M. N., Iqbal, M. A., \& Oba, S. (2020). Bioactive components and radical scavenging activity in selected advance lines of salt-tolerant vegetable amaranth. Frontiers in Nutrition, 7, 587257. http://dx.doi.org/10.3389/fnut.2020.587257. PMid:33330589.

Song, S. Y., Su, P., Wang, L. J., Zou, M. M., \& Sun, X. (2017). Optimization of ultrasonic-assisted extraction by response surface methodology and antioxidant activities of pectic polysaccharide from okra flowers. Shipin Kexue, 38(02), 283-289.

Sun, Y. J., Li, C. S., Lu, F., Wu, X. Q., \& Shen, J. F. (2018). Study on whitening effect of nymphaea hybrid extracts. Journal of Food Science and Biotechnology, 7, 776-783.

Wang, D., Cao, M., Dinh, J., \& Dong, Y. (2013). Methods for creating mutations in C. elegans that extend lifespan. Methods in Melecular Bology, 1048, 65-75. http://dx.doi.org/10.1007/978-1-62703-5569_6. PMid:23929098.

Wang, D.., Wang, Y., \& Shen, L. (2010). Confirmation of combinational effects of calcium with other metals in a paper recycling mill effluent on nematode lifespan with toxicity identification evaluation method. Journal of Environmental Science \& Technology, 22(5), 731-737. PMid:20608510.

Wang, L., Xiao, M. F., Chen, H. P., Liu, B., \& Zeng, F. (2021). Antioxidant activity of oyster peptide component OE-I and its anti-aging effect on Caenorhabditis elegans. Shipin Kexue, Ahead of print. Retrieved from https://kns.cnki.net/kcms/detail/11.2206.TS.20210531.1324.008.html.

Wang, Q. Q., Li, H. Z., Zhang, Z. J., Gao, Z., \& Cui, L. X. (2020). Optimization of encapsulation process of perilla essential oil microcapsule powder. Science and Technology of Food Industry, 41(01), 138-142.

Wang, Y. J., Ma, J. W., Wang, X. Z., Zhou, F., Zhang, B. L., \& Wang, L. F. (2014). Potential anti-aging effects of grape seed procyanidins on Caenorhabditis elegans. Science and Technology of Food Industry, 35(20), 369-373.

Wang, Y. Y., Duan, X., Ren, G. Y., \& Zhou, S. Q. (2018). Optimization of preparation technology and quality of onion essential oil microcapsules. Shipin Kexue, 39(12), 232-238.

Xiao, H., Pan, Z., Deng, L., El-Mashad, H. M., Yang, X.., Mujumdar, A. S., Gao, Z.., \& Zhang, Q. (2017). Recent developments and trends in thermal blanching-A comprehensive review. Information Processing in Agriculture, 4(2), 101-127.http://dx.doi.org/10.1016/j.inpa.2017.02.001.

Xiong, S. L., Lu, F., Shi, M. J., \&Wu, Z. M. (2012). Advancement of evaluation methods about DPPH radical scavenging activity in screening antioxidant. Science and Technology of Food Industry, 33(08), 380-383.

Xu, S. M., Zhang, Z. W., Chen, L. Y., Zeng, Y., Lin, L., \& Yu, F. M. (2021). Advances in study on chemical constituents and pharmacological activities of nymphaea hybrid peck. Journal of Food Science and Biotechnology, 40(6), 18-24. 